\title{
Erratum to: Enhancement of the Ca2+-triggering steps of native membrane fusion via thiol-reactivity
}

\author{
Kendra L. Furber • David M. Brandman • \\ Jens R. Coorssen
}

Published online: 11 November 2010

(C) Springer-Verlag 2010

\section{Erratum to: J Chem Biol}

\section{DOI 10.1007/s12154-008-0013-3}

The authors found following error in the text.

Page 29, paragraph 2, line 22: "extent of fusion, even with $300 \mathrm{mM}$ IA (data not shown)" should read "extent of fusion, even with $160 \mathrm{mM}$ IA (data not shown)"

The online version of the original article can be found at http://dx.doi. org/10.1007/s12154-008-0013-3.

\footnotetext{
K. L. Furber · D. M. Brandman · J. R. Coorssen Department of Physiology and Biophysics, University of Calgary Faculty of Medicine, Calgary, AB T2N 4N1, Canada

J. R. Coorssen

Department of Biochemistry and Molecular Biology,

University of Calgary Faculty of Medicine,

Calgary, AB T2N 4N1, Canada

J. R. Coorssen

Department of Cell Biology and Anatomy,

University of Calgary Faculty of Medicine,

Calgary, AB T2N 4N1, Canada

K. L. Furber · J. R. Coorssen

Hotchkiss Brain Institute,

University of Calgary Faculty of Medicine,

Calgary, AB T2N 4N1, Canada

J. R. Coorssen $(\square)$

Molecular Physiology, School of Medicine,

University of Western Sydney,

Bldg. 30, Campbelltown,

NSW 1797, Sydney, Australia

e-mail: j.coorssen@uws.edu.au
} 